\title{
A POSSÍVEL FLEXIBILIZAÇÃO DOS DIREITOS SOCIAIS E POLÍTICAS PÚBLICAS: SOLUÇÃO PARA O MERCOSUL EM TEMPOS DE CRISE?

\author{
LA POSIBLE FLEXIBILIZACIÓN DE LOS DERECHOS SOCIALES Y POLÍTICAS \\ PÚBLICAS: SOLUCIÓN PARA EL MERCOSUR EN TIEMPOS DE CRISIS?
}

Eduardo Biacchi Gomes*

Andréa Arruda Vaz***

\begin{abstract}
Resumo: O presente artigo teve por objetivo examinar a temática da flexibilização dos direitos trabalhistas como possível solução para o aumento dos postos de trabalho em tempos de crise mundial. Nesse sentido, investigando-se se uma melhor interpretação das normas sociais, pode-seconsiderar a chamada flexibilização positiva? A resposta é afirmativa se o direito do trabalho passa a atuar no sentido de servir de instrumento de emprego e das condições mínimas de vida digna ao trabalhador. Nesse contexto, o artigo apresenta as principais possibilidades de flexibilização, assim como a necessidade de um novo delineamento nesse instituto, de forma a proporcionar um novo olhar e uma nova perspectiva, interpretando a norma do ponto de vista da proteção do empregado e dos propósitos de expansão e de promoção da dignidade da pessoa humana, sob a perspectiva dos direitos humanos dentro de um contexto regional, como é o caso do Mercosul.

Palavras-chave: Flexibilização.Mercosul.Direitos Sociais. Direito do Trabalho. Flexibilização positiva.
\end{abstract}

Resúmen: El artículo hace un análisis del tema de la flexibilización de los derechos laborales como intento para producir mas postos de trabajo en tiempos de crisis mundial. Aqui si pregunta si una interpretación mas favorable de los derechos sociales puede llevar en consideración la llamada flexibilización positiva? La respuesta será afirmativa si el derecho laboral pasa a actuar con la finalidad de tutelar las plazas de trabajo y condiciones minimas de dignidad al trabajador. Así el articulo presenta las posibilidades de flexibilización, bien como propone una nueva forma de análisis del instituto, con la finalidad de interpretar la norma de forma más favorable y protectiva al empleado, así como de acuerdo con la expansion y promoción de la dignidad de la persona humana, dentro de la perspectiva de los derechos humanos dentro del Mercosul.

Palabras clave: Flexibilización. Mercosur. Derecho sociales. Derecho del trabajo. Flexibilización positiva.

\footnotetext{
"Pós-doutor em Estudos Culturais pela Universidade Federal do Rio de Janeiro, com estudos realizados na Universidade Barcelona, Faculdad de Dret; Doutor em Direito pela Universidade Federal do Paraná, PR; Professor pesquisador em Direito da Integração e em Direito Internacional no Centro Universitário Autônomo do Brasil, PR; (UniBrasil), Graduação e Pós-graduação (Especialização e Mestrado); Professor de Direito Internacional da Pontifícia Universidade Católica do Paraná, PR, Consultor do Mercosul para a livre Circulação de Trabalhadores (2005/2006); Rua Imaculada Conceição, 1155, Prado Velho, 80215-901, Curitiba, Paraná, Brasil; ebgomes@me.com

** Mestre em Direitos Fundamentais e Democracia pelo Centro Universitário Autônomo do Brasil, PR; (UniBrasil); Especialista em Direito e Processo do Trabalho pela Pontifícia Universidade Católica do Paraná, PR; Professora de Direito e Processo do Trabalho, Previdenciário e Tributário e Coordenadora do Grupo de Pesquisa Trabalho Decente, Direitos Humanos e Democracia na Faculdade Educacional Araucária (Facear), PR; Avenida das Araucárias, 3803, Thomaz Coelho, 83707-067, Araucária, Paraná, Brasil; andreaarrudavaz@gmail.com
} 


\section{Introdução}

Ao longo da história, as transformações sociais definiram e esculpiram o atual cenário econômico e laboral existente, bem como "[...] a crise social dos anos 60 , questionando o modo de vida proposto pelo capitalismo, [...] ]ensejou um movimento de relegitimação do modo de produção capitalista." (RAMOS FILHO, 2012, p. 307).

A escassez de recursos a partir do século XVI, o aumento populacional e as transformações que a Revolução Industrial trouxe, geram sérios problemas no âmbito do trabalho. As precarizações, a redução de direitos em troca de outros de entendimento como de maior importância apresentam o instituto da flexibilização, que surgiu como tentativa de solução, ainda na Revolução Industrial.

A Revolução Industrial foi um movimento que incidiu em um conjunto de mudanças no âmbito laboral e tecnológico causando alterações no contexto econômico, histórico, social e cultural. Tal movimento iniciou na Inglaterra em meados do século XVIII, sendo disseminado pelo mundo a partir do século XIX.

Sob esse novo contexto mundial da Revolução Industrial, a era essencialmente agrícola foi sendo substituída pela máquina, que chegou para suprir o ser humano enquanto força de trabalho.

Tal fenômeno desencadeia a crise do emprego e da renda, nascendo, assim, o instituto da tradicional flexibilização e precarização nas relações de trabalho, solução encontrada para se tentar reduzir os impactos da revolução tecnológica, no mercado de trabalho, como suposto mecanismo para a resolução e redução de crises econômicas.

A Revolução Industrial possui algumas características marcantes: com a automação dos meios de produção, acontece a diminuição do custo dos produtos e o consequente aumento da lucratividade, porém, o desemprego assolou a Europa, sendo o grande problema revelado pela Revolução, que aflige a classe trabalhadora até os dias atuais.

Ademais “[...] o principal agente de mudança, a força dinâmica que moveu a integração global, foram as empresas multinacionais, que se expandiram em busca de mercados e mão de obra- movimento encabeçado pelas sociedades, por ações inglesas e holandesas e pela Revolução Industrial." (FRIEDMAN, 2014, p. 18). Nesse aspecto, toda a estrutura de produção e até mesmo o modo de vida das sociedades sofrem alterações irreversíveis do ponto de vista social e econômico.

Há o aumento sistêmico da população mundial, que, consequentemente, exige algumas atitudes e formas de se operacionalizarem os mais diversos segmentos da sociedade, entre eles a Economia, a organização social e, claro, o trabalho, enquanto fator de dignidade humana e consequente impulsor econômico e dos demais direitos sociais.

No presente discute-se, além da forma de flexibilização das relações de trabalho, a relativização ou segregação de políticas públicas ou, o que reflete de forma 
negativa nos direitos e garantias do trabalhador, admite-se a possibilidade de uma nova forma de flexibilização, qual seja, a flexibilização positiva de direitos e garantias.

A pesquisa é de todo necessária para acompanhar as tendências flexibilizadoras que objetivam proporcionar mais autonomia da vontade como um papel importante na regulamentação do trabalho e para tal se utilizam métodos, entre eles a desregulação em razão da autorregulação pelas partes, inclusive métodos de flexibilização com objetivos de formulação de novos conteúdos ideológicos (URIARTE; ÀLVAREZ, 2003, p. 169). Ademais, a flexibilização, por vezes, é tida como uma solução, porém, em outros momentos, apenas como uma forma de reduzir direitos, no atual modelo de flexibilização tradicional.

Tais formas consistem e demandam a união entre estados, no desempenho de políticas de ampliação e elastecimento de preceitos e garantias, sejam eles existentes no âmbito interno sejam ainda de forma melhor visualizada em grupos de estados ou países, como é o caso do Mercosul. Assim, o presente trabalho aborda essas duas formas de flexibilização e sua efetividade em tempos de crise no Mercosul.

A flexibilização das normas como forma de solucionar as crises e diminuir o desemprego é discutida, com inúmeros posicionamentos, sendo tida ora como avanço ora como retrocesso.

Em razão da necessidade de se assegurarem direitos para além das fronteiras dos países, em junho de 1919, na denominada conferência da Paz, por meio do Tratado de Versalhes, foi criada a Organização Internacional do Trabalho, com propósitos, entre eles "[...] a universalidade de problemas, o perigo da concorrência desleal entre os Estados, a solidariedade entre os Trabalhadores de diversos países, o desenvolvimento das migrações e a contribuição para a paz." (GUNTHER, 2011, p. 27).

O Surgimento da Organização Internacional do Trabalho vem ao reverso do instituto da Flexibilização, ou seja, busca a sedimentação e a melhor e maior proteção a preceitos de ordem fundamental, por meio das convenções, recomendações, resoluções e declarações, regulamenta e assegura preceitos mínimos.

Nesse contexto, funda-se a Organização Internacional do Trabalho com a necessidade e o intuito de se repensar a proteção aos direitos sociais em uma proporção globalizada, ou seja, com abrangência além das fronteiras de cada país.

A problemática que se enfrenta é a análise do instituto da flexibilização em ambos os aspectos como instrumento para solucionar crises econômicas, com a incidência sobre os direitos sociais. A intenção primordial é o entendimento e a apresentação de fundamentos que justifiquem ou não a adoção desta como solução em tempos de crise no Mercado Comum do Sul, contrapondo-se às garantias fundamentais e inerentes àdignidade humana, interna e externamente a cada país.

A necessidade econômica e os contornos mundiais existentes, assim como os avanços da Ciência, da Tecnologia e inclusive do Direito, em especial no âmbito internacional, são os grandes impulsores do crescimento da aplicabilidade de normas e princípios de cunho internacional, o que Gomes (2001, p. 4) denomina Tendência de Constitucionalização dos preceitos de Direito Internacional. 


\section{$1 \mathrm{~A}$ atual crise mundial}

O cenário mundial econômico na última década enfrentou dois momentos de maior relevância no que se refere a crises mundiais, sendo a primeira iniciada em $2001 \mathrm{com}$ o ataque denominado As Torres Gêmeas,em 11 de setembro de 2001, seguida pela denominada Crise das Hipotecas, nos Estados Unidos da América e pela crise na Europa, desencadeada a partir de 2005.

A crise desencadeada nos Estados Unidos da América decorrente dos ataques terroristas e da crise hipotecária ou também conhecida como "bolha imobiliária", esta decorrente basicamente de uma falta de controle pelos estados, do mercadoe da instabilidade do setor imobiliário, culminou na necessidade de interferência estatal, com a injeção de valores.

As medidas para combater a recessão foram voltadas aos bancos, não ao mercado de trabalho e a políticas de combate ao desemprego e proteção dos direitos sociais, como a moradia, a alimentação e o trabalho.Tal crise ainda cultiva seus frutos, ademais, até o momento, o desemprego é presente, bem como os demais problemas sociais dissodecorrentes.

Atualmente,em relação à existência de uma grande crise, a União Europeia enfrenta uma grave crise econômica, que assola diversos setores e institutos, inclusive os direitos sociais, incluindo nestes o Direito do Trabalho.

Este, diariamente sofre restrições e reduções, desde 2007,quando tal bloco econômico vem tentando contornar a crise que, em 2010, 2011 e 2012, chegou a um patamar insustentável, com medidas de austeridade na tentativa de conter os avanços da crise. Atualmente,

[...] la mayoría de los Estados han adoptado algún tipo de medidas de mejora de la proteción de los parados, refuerzo de los servicios públicos de empleo, programas de trabajos públicos o apoyo a medidas de flexibilidad como, sobre todo, programas de reducción del tiempo de trabajo. (VIÑA, 2010, p. 178).

Tais medidas, conforme cita o autor, aconteceram em 2010, quando ainda se tentava contornar a crise. Atualmente, em um cenário ainda mais precário, diariamente os jornais publicam notícias a respeito de supressões pelos Estados, de direitos sociais, cuja intenção é de que com tais medidas a crise seja superada. A exemplo, cita-se a notícia de que houve manifestação pública em face da medida que aumenta a idade mínima para a aposentadoria. ${ }^{1}$

\footnotetext{
1 Na França,mais de 2,5 milhões se manifestaram, em 07 de setembro, contra o aumento da idade mínima para a aposentadoria (somenteaos 67 anos será possível receber o benefício sem cortes, segundo os planos do Governo). Novos protestos estão previstos para 23 de setembro (A EUROPA..., 2010).
} 
As medidas e reduções apresentadas pelos países contemplam desde a redução de jornada, salários, redução de direitos previdenciários, cortes em pensões, inclusive havendo lesões a direitos adquiridos, como é o caso dos Direitos previdenciários.

Nesse sentido, a crise econômica que devasta a comunidade europeia é fruto de inúmeras questões, entre elas o descaso, principalmente em relação "Del trattati cominutari" e sua maneira de tratar "[...] indirettamente i problemi Del lavoro."sem políticas claras de provisão e manutenção de emprego e trabalho digno (ROCCELLA, 1995, p. 3).

Nesse sentido,manifestações populares na Grécia e na Itália mobilizaram multidões, em especial com o protesto dos servidores públicos que foram diretamente atingidos por medidas de redução de salários e garantias previdenciais, por exemplo (MARTINS, 2009).

Da mesma forma,recente notícia, publicada em 10 de fevereiro de 2012, pelo Jornal Euronews,mostrouo atual estágio de tal crise, bem como que a realidade do trabalhador continua precária e com ataques diretos às garantias fundamentais e sociais, a exemplo da redução do salário dos funcionários públicos em $22 \%$, o que perdurará até 2015, na Grécia (SINDICATOS..., 2012).

Assim, percebe-se que as políticas dos países e parlamentos, ao editar medidas internas de contenção e redução de direitos, sob o título de medidas de austeridade fiscal, estão desvirtuando a própria terminologia. Ademais, medidas de austeridade fiscal deveriam ser pautadas em medidas fiscais e econômicas, e não em medidas para reduções de preceitos e garantias sociais e fundamentais dos trabalhadores.

Enfim, percebe-se que a maioria das medidas de restrição estão diretamente ligadas à redução e à flexibilizaçãode Direitos sociais e preceitos fundamentais, como,por exemplo, reduções salariais e diminuição de garantias previdenciárias atingem diretamente preceitos de ordem fundamental e relacionados à dignidade da pessoa humana.

Ainda que, do ponto de vista econômico e de uma possível forma de regulação de mercado em tempos de crise, tal comportamento seja positivo, há que se admitir, tão somente no âmbito da flexibilização positiva de direitos, sob o risco de lesão a direito e preceitos fundamentais.Ou seja, em um ambiente de crise mundial, as medidas, ainda que inconscientemente, estão direcionadas à supressão de direitos sociais e fundamentais e não em formas de métodos econômicos e governamentais que efetivamente contenham a crise e assegurem preceitos mínimos.

Contextos esses de cunhos trágicos, ademais medidas, de combate a crises deveriam ser prioridade das nações e governos. O combate e a prevenção a sistemas de crise se efetivam em um conjunto de medidas e políticas públicas assecuratórias, em especial a preceitos fundamentais e sociais ao ser humano. 


\section{A flexibilização, uma solução ou retrocesso?}

A atual conjuntura estrutural econômica e social mundial, que se desenvolveu ao longo do tempo, apresentou necessidades as quais se amoldam ao tempo de formas mais variadas. Quanto ao Direito do Trabalho, necessárias são as formas de se viabilizar o trabalho, bem como de assegurar postos de trabalho de forma decente.

Nesse propósito, surgem formas de flexibilização do Direito do Trabalho, que, no atual contexto da Constituição da República Federativa do Brasil de 1988, podem ser realizadas, desde que "[...] permitidas pelo sistema jurídico aplicável." (SUSSEKIND; MARANHÃO, 2005, p. 204).

Os processos econômicos,as alterações da economia e os impactos da globalização abalam diretamente o trabalho e este atinge uma série de outros segmentos da sociedade, causando, às vezes, impactos desastrosos. Barros (2011, p. 2) esclarece que: "A realidade atual confere aos trabalhadores uma situação de extrema exploração, da qual, muitas vezes, não possuem nem o apoio do governo para agir contra essa situação, pois este acaba sendo complacente quanto à forma de trabalho imprópria."

Tal contexto impõe questionamentos a respeito dos motivos pelos quais preceitos fundamentais e inerentes à dignidade humana são mitigados em primeira mão, antes mesmo de questões econômicas e comerciais e até mesmo antes de ações governamentais para protegerem o trabalho e a renda.

O próprio desenvolvimento dos países, atualmente, pode ser afetado pelo modelo de norma trabalhista vigente, visto que o investidor internacional pesquisa mercados com normas mais flexíveis e com conteúdo avançado, para nesses países instalar indústrias e complexos industriais com projeção mundial.

O sistema em si já incentiva a economia a se sobrepor ao trabalho decente e às garantias sociais, uma vez que o sistema econômico visa, justamente, de modo geral, à expansão de Estados com menos direitos e garantias. As garantias do trabalhador se tornaram moeda de negociação para grandes gigantes comerciais com instalações no âmbito transnacional.

A evolução da sociedade, do trabalho e da economia demanda ações dos Governos, da sociedade e, principalmente, atitudes dos entes internacionais, para proteger seus institutos, não obstante, o enigma que se vive no mundo globalizado é a respeito da forma, como e quando agir.

Nesse contexto, a flexibilização, quando aplicada além das previsões normativas constitucionais de cada país, bem como em contrariedade às convenções da Organização Internacional do Trabalho, em especial as que versam a respeito de Direitos Sociais e Fundamentais, e demais tratados e convenções que asseguram garantias inerentes a Direitos Humanos e normas de ordem pública, trata-se, sim, de retrocesso. 
Há que se interpretar os limites da flexibilização de forma tradicional, bem como as formas de execução, ademais uma forma mais flexível de direitos não pode conflitar com garantias sociais e fundamentais ao trabalhador.

Ainda, nesse sentido, vamos além, a flexibilização deveria ser a última forma de se tentar resolver eventual desemprego ou problema econômico, como é a situação atual da Europa. O que se percebe é que o primeiro ponto a ser mitigado são os direitos sociais, em especial o trabalho e não a economia, o Governo com políticas de proteção ao emprego e à renda, enfim, os demais setores do Estado.

Assim, entende-se que a flexibilização de direitos sociais, em especial, nesse caso, os princípios de direito do trabalho, somente poderia ser utilizada após a implantação de políticas econômicas e comerciais para a proteção do trabalho e a contenção do desemprego;bem como após políticas governamentais de fomento de emprego, consumo, manutenção da renda, amparo aos desempregados e outras tantas formas de Administração Estatal, nesse sentido.

O entendimento jurisprudencial em cortes dos países integrantes do Mercosul, de modo geral, enfatiza a proteção dos direitos e das garantias fundamentais ao trabalhador e a todo o ser humano. A exemplo, a Procuradoria Geral da Nação Argentina, em julgamento de recurso interposto por empresa aérea que reduziu salários dos empregados, sob o fundamento de norma coletiva que flexibilizava tal condição.

A Corte entendeu que era devida a multa imposta ao empregador pelo descumprimento constitucional sob o fundamento, entre outros, de que as garantias fundamentais aos trabalhadores

[...] es un principio arquitectónico del Derecho Internacional de los Derechos Humanos que el Estado está obligado, por un lado, a "respetar"los derechos y libertades reconocidos en los tratados que ratifica, y, por el otro, a organizar el poder público para garantizar a las personas bajo su jurisdicción el libre $y$ pleno ejercicio de los derechos humanos. (A1792 42).

Nesse contexto, o entendimento jurisprudencial é no sentido de que ao estado compete a implementação de políticas públicas voltadas a uma maior proteção e efetivação de direitos e garantias inerentes à dignidade humana.

Ademais, a flexibilização é uma possibilidade latente no mundo desenvolvido e principalmente em situações de crise, como é o caso da União Europeia atualmente, não obstante tal instituto jamais poderia superar o instituto da proteção a direitos e garantias fundamentais, relacionadas a normas de Direitos Humanos, bem como aos Direitos Sociais.

O confronto desses institutos traz desequilíbrio e vulnerabilidade a preceitos gerais de proteção, configurando-se verdadeiro retrocesso social.

Nesse contexto, para que a flexibilização seja um instituto que apresente soluções em tempos de crise, há que se aplicá-lo deforma positiva, com a implementação de políticas que reforcem as garantias fundamentais e os preceitos inerentes àdignidade da pessoa humana, como medidas governamentais para prevenir ou solucionar crises. 


\subsection{Mercosul: um modelo de bloco econômico}

A colonização dos países que atualmente integram o Mercosul aconteceu de acordo com o potencial de riquezas baseadas na extração de pedras preciosas e agricultura, em especial a cana-de-açúcar.

Tal potencialidade proporcionou a trazida de escravos em decorrência das crises na Europa, bem como da superpopulação nesse continente, aconteceu aimigração em massa, com a consequente miscigenação de raças e povos na América Latina,apartir do século XIX (SANCHES, 1998, p. 25-26).

Gomes (2001, p. 46) elucida que:

Na década de 80 sentiram os países sul-americanos, principalmente Brasil e Argentina, a necessidade de fomentar seu comércio interno, o que culminou na formação de um mercado econômico entre ambos, com a participação posterior do Paraguai e do Uruguai e na consequente celebração do Tratado de Assunção, em 1991, que instituiu o Mercosul.

O Mercosul atualmente é composto pelo Brasil, Argentina, Paraguai (temporariamente suspenso), Uruguai e Venezuela, que possuem cada um a sua individualidade, legislações, economia e culturas próprias, o que causa a maioria dos impasses entre os integrantes do bloco.

Há uma convergência quando o assunto é proteção aos direitos sociais, ainda que do ponto de vista formal. Não obstante "No continente Sul-americano, os objetivos dos processos integracionistas foram diferentes dos verificados no continente europeu, pois neste as razões foram puramente econômicas e também pacifistas." (GOMES, 2001, p. 41).

Enquanto a integração da União Europeia teve objetivos fundamentados na solidariedade, na liberdade e nos pactos sociais comunitários, percebe-se que na América Latina as intenções integrativas são totalmente diferentes, qual seja, voltadas para a economia. A convergência entre os dois blocos econômicos em questão está nos objetivos pacificadores.

Atualmente, uma questão que se discute no bloco com o ingresso da Venezuela é a forma e o contexto legislativo e governamental desse país. A discussão acontece em decorrênciado fato social combatido pela Organização Internacional do Trabalho, denominado "dumping social". Tal instituto é caracterizado pela degradação da forma coletiva do trabalho. Nesse sentido, os tribunais brasileiros têm se manifestado:

DUMPING SOCIAL. INDENIZAÇÃO POR DANO SOCIAL COLETIVO. Restando comprovada a ocorrência reiterada de acidentes do trabalho nas dependências da reclamada, em virtude da insegurança do meio ambiente de trabalho, não há óbice para que o Juízo imponha penalidade sobre a empresa demandada, ainda que não haja pedido específico, em virtude de seu compromisso ético com a proteção da dignidade da pessoa humana e do trabalho[...] (BRASIL, 2012). 
Sussekind e Maranhão esclarecem que: "Alguns países implantaram, ou procuram implantar, os sistemas e instrumentos de modernidade tecnológica; outros, porém, para concorrer no mercado internacional, agravam as condições de trabalho, num retorno ao início do século XIX."

Tal entendimento descreve o retrocesso como consequência do desenvolvimento tecnológico e da transnacionalidade das grandes corporações mundiais.

Na mesma linha, o "dumping social” é uma forma de concretização da segregação do trabalho, bem como de degradação dos direitos sociais e da dignidade da pessoa humana,assunto que no Mercado Comum do Sul é objeto em menção na Declaração Sociolaboral do Mercosul.

\section{Da flexibilização positiva de direitos dos trabalhadores e previsão normativa respeito, no Mercosul}

O Mercosul, bloco econômico fundado por meio do Tratado de Assunção, cujos princípios que regem tal Mercado Comum estão estabelecidos no artigo $1^{\circ}$, quais sejam a livre circulação de bens, serviços e fatores produtivos, bem como a eliminação de direitos alfandegários e restrições tarifárias, regulamentação de tarifas comuns e a adoção e coordenação de políticas macroeconômicas voltadas aos países integrantes do grupo.

Ainda, um dos princípios e dos maiores desafios atuais é a busca pela harmonização da legislação e dos projetos integracionistas.

Nesse contexto, poder-se-ia pensar em uma forma de se flexibilizar de forma positiva direitos e garantias vigentes em determinados países do bloco para beneficiar, a exemplo, trabalhadores de todo o Mercosul. A harmonia legislativa e integracionista ainda é um dos grandes desafios, ademais cada país possui constituições e legislações próprias, a respeito da flexibilização de direitos.

No direito brasileiro, a flexibilização foi regulamentada no âmbito constitucional na Constituição de 1988, o que Carli (2005, p. 59) explica da seguinte maneira: "A flexibilização no Brasil, só foi elevada ao patamar de norma constitucional a partir da Carta Magna de 1988, de acordo com as circunstâncias socioeconômicas, vem flexibilizando suas normas trabalhistas [...]"

Para Grillo (2011, p. 286-287) em um contexto de flexibilização in pejus do Direito do Trabalho, em detrimento a direitos e garantias fundamentais que acontecem tanto pelo legislador quanto pelo Poder Judiciário, o Supremo Tribunal Federal contribuiu "[...] para a reconstrução jurisprudencial de um direito do trabalho senão desregulado, ao menos flexibilizado." Nesse aspecto, percebe-se que há uma promoção de flexibilização lesiva ao empregado, inclusive partindo das cortes constitucionais dos países, como é o caso do Brasil.

Na Argentina, conforme esclarece Carli (2005), a flexibilização do ponto de vista legislativo inicia em 1991 com a Lei Nacional de Emprego. A Argentina, na década de 1990, passou por uma enorme crise, fato de conhecimento mundial, o que fomentou a 
necessidade de mudanças no âmbito trabalhista, entre as quais, os contratos por tempo determinado, os contratos temporários, com prazo determinado ou por temporada, os contratos de aprendizagem, limitados a trabalhadores entre 15 e 28 anos.

A Constituição paraguaia,promulgada em 1992, prevê a contratação por prazo determinado, igualdade entre homens e mulheres, jornada de trabalho de 48 horas semanais, férias anuais, estabilidade no emprego e indenização em caso de dispensa.

No Uruguai vige a desregulamentação e a intervenção mínima do Estado. Em tal Estado,o poder negocial do sindicato é absoluto, salvo se houver violação a preceitos mínimos, fundamentais ao ser humano, bem como às normas de Direitos Humanos previstas no âmbito interno ou internacional.

A partir de primeiro de maio de 2012, vige na República Bolivariana da Venezuela a denominada Ley Orgánica Del Trabajo para los Trabajadores y las Trabajadoras (LOTTT), promulgada pelo Decreto n. 8.938, que revogou, Ley Organica del Trabajo de1997 (VENEZUELA, 2012).

Tal instrumento normativo apresenta algumas possibilidades no que diz respeito à possibilidade de flexibilização, entre as quais a ampla e irrestrita possibilidade de negociação pelos sindicatos, que estão adstritosà limitação relacionada a garantias mínimas inerentes a preceitos fundamentais e Direitos Humanos.

A Declaração Sociolaboral do Mercosul surge em 1998, com propósitos voltados à proteção do empregado e à reafirmação dos principais instrumentos internacionais de proteção ao Ser Humano,bem como documentos e orientações que apresentam preceitos relacionados a Direitos Humanos, proteção aos Direitos Sociais, enfim, relacionados ao indivíduo enquanto sujeito de direitos e protegido por normas fundamentais mínimas, de ordem interna e externa aos países do bloco econômico.

Entre preceitos de promoção da igualdade, combate à discriminação e demais previsões protetivas estão as denominadas formas de flexibilização positiva de Direitos, possíveis e até mesmo facilitadas quando se trata de um bloco econômico.

A tanto se pensar na possibilidade de formas de proteger o emprego, a renda e a promoção do trabalho decente, conclui-se que há a possibilidade de formas de flexibilização ao reverso, não para diminuir direitos, que de certa forma sempre causam algum prejuízo para o empregado.

Assim, diante do estudo da Declaração Sociolaboral do Mercosul e de outros ordenamentos, nesse sentido, conclui-se pela possibilidade de formas positivas de flexibilização, as quais demandam estudo e aprofundamento específico.

Exemplo prático dessa proteção e flexibilização positiva de direitos sociais no âmbito interno, formalizou-se em 06 de março de 2013, no Brasil, com a publicação do Decreto n.7.943, de 05 de março de 2013, que Institui a Política Nacional para os Trabalhadores Rurais Empregados.

Tal Decreto possui objetivos puramente voltados ao fortalecimento e à efetivação de direitos sociais a uma parcela de trabalhadores. Tal Decreto possui a meta de implantação de políticas públicas de inclusão social desses trabalhadores, bem como o fomento de discussões acerca de políticas públicas nesse segmento social. 
A flexibilização de forma positiva está justamente na possibilidade de ampliação de Direitos existentes no Direito Interno, com a expansão para a vigência e aplicação em todos os países do bloco, ou países que aceitem tal pactuação.

Não obstante ser mais evidente no âmbito de um bloco econômico resta comprovado que é possível a implantação de formas positivas de flexibilização de direitos, também internamente em cada país,como agiu o Brasil, conforme exposto, ao integrar uma parcela tão excluída em políticas de fortalecimento de direitos sociais, quais sejam, os trabalhadores empregados no meio rural.

Assim, a flexibilização e os processos de integração são instrumentos aliados à promoção de igualdade, solidariedade e proteção de direitos, isso tanto no que se relaciona ao Direito do Trabalho quanto para outros ramos, como é o caso nato do Mercosul, as garantias econômicas sociais e comerciais.

O primeiro exemplo de uma forma de flexibilização positiva, no contexto do Mercosul, constata-se no artigo $4^{\circ}$ da Declaração Sociolaboral, que versa:

Todo trabalhador migrante, independentemente de sua nacionalidade, tem direito à ajuda, informação, proteção e igualdade de direitos e condições de trabalho reconhecidos aos nacionais do país em que estiver exercendo suas atividades, em conformidade com a legislação profissional de cada país. (DECLARAÇÃO SOCIOLABORAL DO MERCOSUL, 1998).

Ainda, o mesmo artigo versa a respeito do comprometimento dos países integrantes do bloco na adoção de medidas para proteger o trabalhador em países do bloco.

A implantação de um sistema flexível, no qual o trabalhador é protegido para desempenhar o labor em outros países ou em áreas fronteiriças, é uma forma de proteção, mas também de flexibilização positiva da norma, para abranger um número maior de trabalhadores, bem como estabelecer maiores proteções no trabalho, na saúde, na educação e em demais direitos sociais e fundamentais ao ser humano.

Os Estados-partes comprometem-se a propiciar e a desenvolver formas preventivas e alternativas de autocomposição dos conflitos individuais e coletivos de trabalho, fomentando a utilização de procedimentos independentes e imparciais de solução de controvérsias.

O artigo 14, mais uma vez, de forma exemplificativa, versa a respeito do fomento ao emprego, no âmbito do bloco, ou seja, além das políticas internas de promoção ao emprego, “[...] os Estados-Partes comprometem-se a promover o crescimento econômico, a ampliação dos mercados interno e regional e a executar políticas ativas referentes ao fomento e criação do emprego, de modo a elevar o nível de vida e corrigir os desequilíbrios sociais e regionais." (DECLARAÇÃO SOCIOLABORAL DO MERCOSUL, 1988).

Essa forma de fomento e integração fortalece o trabalho e sedimenta preceitos de proteção;mesmo que do ponto de vista formal, ainda assim há a esperança de que o próximo passo seja a luta pela efetivação da norma posta. 
A efetivação de um sistema de promoção de mercados de trabalho interna e externamente também é uma forma de flexibilização positiva;ademais, propicia ao trabalhador fontes de informação a respeito tanto do seu país quanto de outros integrantes do bloco.

Essa condição, se praticada pelos países, pode incentivar o exercício profissional em outros países, bem como o conhecimento pelo trabalhador das garantias que possui no âmbito internacional, bem como é um instrumento de efetivação da liberdade profissional.

Tais formas, por certo, colaboram com um sistema de flexibilização positiva e colaborativa com o trabalho decente e com os preceitos de proteção àpromoção da dignidade humana.

Assim, a Declaração Sociolaboral do Mercosul apresenta formas de flexibilização, as quais se entendem positivas e vão ao reverso do instituto tradicional da flexibilização discutido atualmente, algumas delas já citadas, apenas a título exemplificativo.

Da mesma forma, alguns artigos, a título exemplificativo, do Acordo Multilateral de Seguridade Social elaborado em 1997, firmado pelos países integrantes do Mercosul, já possuem esse caráter de positividade com a flexibilização de algumas normas, até então internas a cada país membro.

$\mathrm{O}$ artigo $4^{\circ}$ constitui a base fundamental do Acordo e versa que: "O trabalhador estará submetido à legislação do Estado-Parte em cujo território exerça a atividade laboral." (ACORDO MULTILATERAL DE SEGURIDADE SOCIAL DO MERCADO COMUM DO SUL, 1997).

A partir de então, o trabalhador estará submetido e, portanto, segurado, no país em que exerça o trabalho. Por certo que, nesse sentido, há inúmeras discussões acerca da abrangência dos direitos, da forma de controle, das contribuições, da carência, entre outros impasses que disso podem surgir, contudo, para essa tentativa de positivar a abrangência da seguridade a todos os países integrantes do Mercado Comum do Sul, há ainda,do ponto de vista formal, a busca por uma maior abrangência do rol de proteção ao empregado. Este que, ao exercer suas atividades em outro país do bloco, agora pode recorrer à segurança e à proteção na área da Saúde, Previdência e Assistência, ainda que do ponto de vista interpretativo do Direito Previdenciário Brasileiro.

Tal possibilidade é de todo benéfica ao empregado e aos seus familiares, assegurando-lhes um alargamento na proteção previdenciária, bem como é instrumento de pacificação social e inclusão laboral. Normas nesse sentido podem, ao longo do tempo, com amadurecimento e responsabilidade, sobreporem o trabalho àeconomia, do ponto de vista mitigatório.

Os artigos subsequentes do Acordo Multilateral tratam da concessão de regimes de aposentadoria, formas de concessão e procedimentos para a efetivação de benefícios, também contendo flexibilizações positivas, que asseguram ao trabalhador maior possibilidade e segurança previdenciária, ao longo do bloco econômico. 
Nesse aspecto, importante compreender que "[...] com as declarações dos direitos fundamentais dos trabalhadores que foram difundidos internacionalmente através da OIT, houve o movimento de reconquista de valores e de direitos perdidos no processo de mundialização da economia." (GOLDSCHMIDT; FINCO, 2012, p. 299). Essas declarações, por vezes, vêm reafirmar preceitos e garantias já expostos em outros instrumentos, no objetivo de reiterar a existência e a necessidade de concretização desses preceitos.

Ademais, esclarece-se que o presente artigo se limitou a analisar os dois instrumentos citados;porém, há um vasto número de acordos, declarações, protocolos e recomendações elaboradas no Mercado Comum do Sul, nos grupos de trabalho, reuniões, entre outros, que convergem nesse mesmo sentido.

Assim, o entendimento, ousado e questionável da existência de formas de flexibilização positiva no âmbito do Mercosul, demonstra que o Instituto possui outro lado, outra forma de aplicação, quando se tratam de blocos econômicos e processos integracionistas, estes como instrumento de ratificação e transformação social, bem como de proteção a preceitos de proteção aos Direitos Humanos, sendo o Direito ao Trabalho e este de forma decente, garantias fundamentais a uma vida com dignidade, inclusive aos habitantes nos países integrantes do Mercosul.

\section{Considerações finais}

O artigo em questão apresentou umbreve estudo a respeito da flexibilização de direitos, que surge ao longo dos anos, como medida e tentativa de solucionar crises econômicas, sob o fundamento de reduzir o desemprego, no âmbito dos direitos sociais, com especial repercussão no Direito do Trabalho.

A principal dicusssão a respeito do Instituto da Flexibilização é a inevitável mitigação do Direito do Trabalho muito antes de qualquer outra providência possível em relação àeconomia, ao comércio, às políticas internas de proteção ao trabalho, nos países. Enfim, o que se percebe, principalmente no anseio de crises econômicas, é que um dos primeiros institutos a ser afetado é o trabalho, este enquanto instrumento de sedimentação da Dignidade Humana.

A busca por respostas e soluções fez deste artigo um estudo a respeito da flexibilização no âmbito do Mercosul, como solução para os tempos de crise.

Nesse contexto, a conclusão pela existência de formas positivas de flexibilização, quando se tratam de blocos, mostra-se possível, tanto que são comprovadamente existentes no Mercosul. Tais devem ser utilizadas, com os demais instrumentos existentes, nos âmbitos nacional e internacional, na forma de normatização, orientações,pactos sociais, políticas públicas,estes como recursos “[...] sempre que um país se debate com uma situação profunda de crise econômica e política, gerando enorme insatisfação no povo." (GUNTHER, 2011, p. 97). 
Os processos integracionistas e a busca pela implantação de institutos, como, por exemplo, a proteção previdênciária ao trabalhador ao longo do bloco, a possibilidade de liberdade territorial para o desempenho do Trabalho, também denominada Livre Circulação de Trabalhadores, são instrumentos importantes na construção e sedimentação da proteção,não apenas instrumentos de proteção, mas também de efetivação de processo de integração, este como instrumento de proteção ao trabalho, aos Direitos Sociais e aos princípios inerentes àproteção aos Direitos Humanos, interna e internacionalmente.

A flexibilização positiva de Direitos é um forte instrumento de proteção do trabalho decente, em especial, o que demanda novos estudos e um aprofundamento também no que se refereaos demais institutos dos Direitos sociais,em especial a saúde e a educação. Assim, aquilo que era possível apenas no território de um país, pode, por meio de processos de integração e de flexibilização positiva da norma, ser estendido ao longo de todo o bloco econômico.

Finalmente, conclui-se que a efetivação da flexibilização positiva de direitos é a solução para o Mercosul, não apenas em tempos de crise, mas também para a prevenção desta. Não obstante, no que diz respeito à flexibilização de forma convencional, quando direitos são reduzidos, suprimidos ou segredados em nome de uma expectativa de solução a crises, não há nenhuma pesquisa que ateste tal eficiência, motivo pelo qual, reconhecida neste como retrocesso social e não como instrumento para a redução de desemprego e efetivação de direitos sociais.

\section{Referências}

ACORDO MULTILATERAL DE SEGURIDADE SOCIAL DO MERCADO COMUM DO SUL. Montevidéu, 1997. Disponível em: < http:/www.stf.jus.br/arquivo/cms/forumCorteSupremaNorma/forumCorteSupremaNorma_AP_75317.pdf $>$. Acesso em: 18 ago. 2012.

A EUROPA vai às ruas. Outras Palavras, São Paulo, 14 set. 2010. Disponível em: <outraspalavras.net/outrasmidias/uncategorized/europa-vai-as-ruas-2.>. Acesso em: 12 fev. 2012.

ARGENTINA.Constituição Nacional. Disponível em: < http://www.senado.gov.ar/ web/interes/constitucion/cuerpo1.php>. Acesso em: 19 ago. 2012.

ARGENTINA.VARG-2009-X-XXX 24.02.2009 A1792 42, Corte Suprema de Justiça da Nação Argentina. Julgado em 24 fev. 2009. Buenos Aires, 2009. Disponível em:<http://www.cortesmercosul.jus.br/forum/jurisprudencia/detalharJurisprudencia.asp?seqJurisprudencia =721>. Acesso em: 14 mar. 2013. 
BARROS, Ludmila Silva. A Globalização, os Direitos do Trabalhador e Cidadania. Cadernos da Escola de Direito e Relações Internacionais, Curitiba, v. 15, p. 16782933, 2011. Disponível em:<http://www.unibrasil.com.br/arquivos/publicacoes/ index.asp? arquivo $=$ cad _e_dir-relacoes-internacionais.htm $>$. Acesso em: 29 ago. 2012.

BRASIL. Acórdão -Processo 0205300-60.2009.5.04.0404 (RO). 9a Turma. Relatora: Maria Madalena Telesca.Diário de Justiça do Estado do Rio Grande do Sul, 01 fev. 2012. Disponível em:<http://www.trt4.jus.br/portal/portal/trt4/consultas/jurisprudencia/acordaos >.Acesso em: 29 ago. 2012.

BRASIL. Consolidação das Leis Trabalhistas de 1943. 3. ed. São Paulo: RT, 2012.

BRASIL. Constituição da República Federativa do Brasil de 1988. 3. ed. São Paulo: RT, 2012.

BRASIL. Decreto n. 7.943, de 05 de março de 2013. Institui a Política Nacional para os Trabalhadores Empregados.DiárioOficial da União, Brasília, DF, 06 mar. 2013. Disponível em:<http:/www.planalto.gov.br/ccivil_03/_Ato2011-2014/2013/Decreto/ D7943.htm >. Acesso em: 12 mar. 2013.

CARLI, Vilma Maria Inocêncio. A Flexibilização dos contratos de Trabalho. Campinas: ME Editora, 2005.

DECLARAÇÃO SOCIOLABORAL DO MERCOSUL. 1998. Disponível em:<http:// www.mercosul.gov.br/declaracoes/1998/declaracionsociolaboraldelmercosur?searc hterm $=$ declara\%C3\%A7\% C3\% A3o+sociolaboral $>$. Acesso em: 18 ago. 2012.

GOLDSCHMIDT, Rodrigo; FINCO, Suzane. Os direitos fundamentais e as ações afirmativas da dignidade da pessoa humana como instrumentos de resistência àprecarização dos direitos trabalhista. In: SIMPÓSIO INTERNACIONAL DE DIREITO: DIMENSÕES MATERIAIS E EFICACIAIS DOS DIREITOS FUNDAMENTAIS, 2., 2012. Chapecó. Anais... Chapecó, 2012. Disponível em:<http:// editora.unoesc.edu.br/index.php/simposiointernacionaldedireitosfundamentais $>$. Acesso em: 16 set. 2014.

GOMES, Eduardo Biacchi. Blocos econômicos e solução de controvérsias:uma análise comparativa a partir da União Européia e MERCOSUL. Curitiba: Juruá, 2001.

GUNTHER, Luiz Eduardo. A OIT e o Direito do Trabalho do Brasil. Curitiba: Juruá, 2011.

HERNANDEZ ALVAREZ, Oscar;URIARTE, Oscar Ermida. Crítica de La Subordinación. Civitas, Revista espanõla de derecho del trabajo, n. 116, p. 167-190, 2003. Disponível em: <http://dialnet.unirioja.es/servlet/articulo codigo $=495585>$. Acesso em: 16 set. 2014. 
MARTINS, Antonio. Valenzuela, 11 set. 2009. Disponível em: < http://www.outraspalavras.net/2010/09/11/ricos-decadentes-malvados/>. Acesso em: 09 mar. 2013.

PROTOCOLO DE ADESÃO DA REPÚBLICA BOLIVARIANA DA VENEZUELA AO MERCOSUL 2012. Disponível em: <http://www.mercosul.gov.br/tratados-e-protocolos/protocolo-de-adesao-da-republica-bolivariana-da-venezuela-ao-mercosul/ protocolo-de-adesao-da-republicabolivariana-da-venezuela/> .Acesso em: 04 ago. 2012.

FRIEDMAN, Thomas L.O mundo é plano: o mundo globalizado no século XXI.Tradução Cristina Serra, Sergio Duarte, Bruno Casotti eCristina Cavalcanti. 3. ed. São Paulo: Companhia das Letras, 2014.

RAMOS FILHO, Wilson. Direito Capitalista do Trabalho: história, mitos e perspectivas no Brasil. São Paulo: LTr, 2012.

COUTINHO, Sayonara Grillo;SILVALeonardo da. Direitos Fundamentais, Garantismo e Direito do Trabalho. Revista do TST, Brasília, v. 77, n. 3, jul./ set. 2011. Disponível em:<http://www.tst.jus.br/web/biblioteca/2011-vol.-77/-/ document_library_display/D3yj/view/2684887/12568?_110_INSTANCE_D3yj_ redirect $=$ http $\% 3 \mathrm{~A} \% 2 \mathrm{~F} \% 2 \mathrm{Fwww}$.tst.jus.br\%2Fweb\%2Fbiblioteca\%2F2011-vol.-77\%3Fp_p_id\%3D110_INSTANCE_D3yj\%26p_p_lifecycle\%3 D0\%26p_p_ state\%3Dnormal\%26p_p_mode\%3Dview\%26p_p_col_id\%3Dcolumn-2\%26p _p_col_pos\%3D2\%26p_p_col_count\%3D5 > . Acesso em: 20 set. 2014.

SINDICATOS Gregos chumbam nova vaga de austeridade.Euronews, 10 fev. 2012. Disponível em:<http://pt.euronews.net/2012/02/10/sindicatos-gregos-chumbam-nova-vaga-de-austeridade>. Acesso em: 12 fev. 2012.

SUSSEKIND, Arnaldo;MARANHÃO, Délio. Instituições de Direito do Trabalho. 22. ed. atual. por Segadas Viana e João de Lima Teixeira Filho. São Paulo: LTr, 2005.

TRATADO DE ASSUNÇÃO.Tratado para a Constituição de um Mercado Comum entre a República Argentina, a República Federativa do Brasil, a República do Paraguai e a República Oriental do Uruguai. Disponível em:<http://www.mercosul.gov. br/tratados-e-protocolos/tratado-de-assuncao-1>. Acesso em: 17 ago. 2012.

VENEZUELA, Constituição Federal de 1999.Disponível em: <http://pt.scribd.com/ doc/97025685/Constituicao-Bolivariana-de-1999 > . Acesso em: 18 ago 2012.

VENEZUELA. Ley Orgánica Del Trabajo para los Trabajadores y las Trabajadoras (LOTTT). Disponível em:<http://www.tsj.gov.ve/legislacion/LeyesOrganicas/46.-GOE_6076.pdf>. Acesso em: 04 ago. 2012. 
VIÑA, Jordi Garcia. AZEVEDO, André Jobim de; VILLATORE, Marco Antonio (Coord). La Crisis Económica y los mecanismos que pueden proponer desde la seguridad social. In:Direito do Trabalho - XIV Jornada Luso-Hispano-Brasileira. Curitiba: Juruá, 2010.

Data da submissão: 09 de maio de 2013 Avaliado em: 07 de julho de 2014 (Avaliador A) Avaliado em: 03 de julho de 2014 (Avaliador B) Avaliado em: 22 de julho de 2014 (Avaliador C) Avaliado em: 20 de agosto de 2014 (Avaliador D)

Aceito em: 13 de abril de 2015 
